\title{
Provision of care through telemedicine during a natural disaster: a case study
}

\author{
Elizabeth C. Pasipanodya $\mathbb{1}^{1} \cdot$ Kazuko Shem $^{2}$
}

Received: 4 May 2020 / Revised: 16 June 2020 / Accepted: 17 June 2020

This is a U.S. government work and not under copyright protection in the U.S.; foreign copyright protection may apply 2020 . This article is published with open access

\begin{abstract}
Introduction As the frequency and intensity of natural disasters increases, disaster preparedness is necessary for individuals with disabilities, including those with spinal cord injury (SCI). However, despite vulnerability to poorer outcomes, disaster preparedness for individuals with SCI is inadequate. Telemedicine has been effectively used to mitigate the impact of natural disasters. In this case study, we describe the provision of clinical care, via telemedicine, to an individual with SCI who was affected by the California Valley Fire in 2015.

Case presentation The individual described was an adult who sustained a SCI. Before discharge from acute inpatient rehabilitation, they enrolled in a research study, through which they received outpatient SCI-specific care via telemedicine (teleSCI). The participant attended several teleSCI visits prior to the start of the Valley Fire. In the midst and immediate aftermath of prolonged wildfire, and despite experiencing significant personal loss as a result of the fire, the participant continued to receive teleSCI services. TeleSCI was used to address emergent and extant medical concerns and to facilitate replacement of medical supplies and equipment destroyed by fire.

Discussion TeleSCI was used to provide continuity of care and was responsive to the needs of an individual with SCI severely affected by wildfire. Emergency preparedness that meets the needs of persons with disabilities is critical during times of crisis. Telemedicine may be an effective tool that can be applied to meet the medical needs of individuals with SCI and to mitigate the impact of disasters.
\end{abstract}

\section{Introduction}

Disaster preparedness is increasingly critical as the severity and impact of natural disasters grows as a result of global climate change [1-7]. Coinciding with the rise in average temperatures, more earthquakes, tornadoes, hurricanes, and wildfires causing significant property damage and loss of life have been recorded in the United States in recent decades than previous ones [1, 3, 8-10]. Although disaster preparedness to mitigate the negative impact of natural disasters is vital for every person, it is particularly so for

Kazuko Shem

Kazuko.Shem@hhs.sccgov.org

1 Rehabilitation Research Center, Santa Clara Valley Medical Center, San Jose, CA, USA

2 Department of Physical Medicine and Rehabilitation, Santa Clara Valley Medical Center, San Jose, CA, USA individuals with disabilities, including those with spinal cord injury (SCI), who are more vulnerable during crises [11-13].

During natural disasters and other crises, persons with SCI encounter greater barriers to mobility and to maintaining their physical and mental health. For instance, the majority of US individuals with SCI rely on wheelchairs or scooters; however, natural disasters typically result in greater mobility challenges such that individuals with SCI may experience difficulties with evacuation, transportation, and access to customized living quarters [14, 15]. Furthermore, disasters may result in disruptions to receiving healthcare. Given the high degree of psychiatric comorbidities (e.g., depression, anxiety, and post-traumatic stress disorder) among individuals with SCI and their unique physical health concerns (e.g., spasticity and chronic pain), the stress and disruption caused by natural disasters may exacerbate physical and mental health conditions among individuals with SCI [16-21]. However, despite vulnerability to poorer outcomes in the context of natural 
disasters, studies examining disaster preparedness among individuals with SCI and other disabilities suggest inadequate planning and a lack of specific strategies for evacuation, survival, and care needs [22-25].

Telemedicine is the provision of clinical services remotely, through telecommunications-based networks, usually to individuals who might otherwise be restricted from accessing healthcare due to environmental constraints [26]. The use of telemedicine for routine encounters has steadily increased and a review of telemedicine research studies suggests efficacy for treatment and follow-up among individuals with SCI [27]. As telemedicine enables healthcare visits when in-person visits would be otherwise inconvenient or impossible, its relevance for disaster preparedness and mitigation is clear. Indeed, telemedicine has been used to provide care and to support relief efforts during disaster situations [28, 29]. In this case study, we describe the provision of clinical care, via telemedicine, to an individual with SCI who was affected by the Valley Fire in 2015. To date, the Valley Fire is recorded as the 5th most destructive fire in the state of California, burning 76,067 acres of land, destroying 1955 buildings, and causing 4 deaths from its start on September 12, 2015 till its containment on October 15, 2015 [30].

\section{Case presentation}

The individual described in this case report was an adult who sustained a complete traumatic SCI several months before the 2015 Valley Fire. They underwent acute inpatient rehabilitation at Santa Clara Valley Medical Center (SCVMC) and, at discharge, were independent in most activities of daily living including wheelchair transfers and maneuverability. The individual with SCI also followed an intermittent catheterization program for bladder management and a bowel management program consisting of laxatives and stool softeners with digital stimulation and evacuation. Prior to returning to their private residence in the north central portion of California, a significant distance away from SCVMC, they enrolled in a telemedicine for SCI (teleSCI) study (SCiPad; Craig H. Neilsen Foundation Quality of Life Grant \#296161), through which they received remote SCI-specific care from a board-certified SCI specialist. As part of the study, the participant received a tablet (Apple iPad Air) with a 6-month cellular data plan as well as a home blood pressure machine for selfmonitoring [31, 32]. The participant's teleSCI visits were completed through the FaceTime application. FaceTime uses end-to-end encryption to prevent interception and decryption of data while in transit between devices, satisfying the Health Insurance Portability and Accountability Act standards for the protection of electronic health information [33]. TeleSCI visits with the physician were able to be scheduled within a day of request and a program coordinator, who was available to all participants for nonemergency needs during regular business hours, liaised between the participant and the physician outside of scheduled appointments. All applicable institutional and governmental regulations concerning the ethical use of human volunteers were followed during the SCiPad study.

Prior to the Valley Fire, the participant attended several teleSCI visits with the physician; visits typically addressed comorbidities and concerns common among individuals with SCI (e.g., neurogenic bladder, pressure sores, urinary tract infections, and deep vein thrombosis) [20, 21]. Using FaceTime's video capabilities, the physician could see and hear the participant, allowing visual and auditory aids that were helpful in informing the physician's assessment of the participant's physical and mental well-being. Blood pressure readings were also taken by the participant and reported to the physician at each teleSCI visit. In addition, as the participant received primary care near their place of residence and had routine lab work, test results and participant notes were reciprocally available to the SCI physician and the participant's primary care doctor for coordination of care.

Within days of the start of the Valley Fire, the participant attended a scheduled teleSCI visit and they reported losing their home to wildfire and temporarily moving in with their significant other, whose residence remained intact. The participant additionally reported having to live with other acquaintances and family members who were similarly displaced by the fire. Furthermore, the participant reported that although they still had their manual wheelchair, most of their supplies and durable medical equipment (DME), including commode/shower bench, electric compression devices, standing frame, and equipment for home exercise were lost. Thus, the participant's new medical needs at that time were to replace essential DME and supplies; these were immediately ordered and promptly authorized by the participant's insurance. In addition to addressing pressing concerns, existing concerns were reviewed and follow-up teleSCI appointments were scheduled.

In between teleSCI visits, and while efforts to contain the Valley Fire continued, the participant communicated with the research coordinator and physician via secure email regarding their physical health concerns, including lower extremity swelling and pressure sores, and the participant provided images for the physician to review. A prescription to replace heel float boots and stretching straps lost in the fire was provided to the participant and they were instructed to wear heel protectors and to continue to monitor areas with active pressure sores. The participant additionally corresponded with the physician regarding obtaining authorization for a vehicle modified for a driver with 
disabilities. Subsequent to this, follow-up teleSCI visits discussed routine participant concerns and monitored participant mood during this period of high stress. Within six months of the start of the fire, the participant relocated to a new house and re-established their lifestyle.

\section{Discussion}

This case report describes the use of teleSCI to provide care to an individual with SCI in the midst and immediate aftermath of a natural disaster. As a result of the Valley Fire, the individual with SCI lost their home, most of their possessions, and the majority of their adaptive devices and medical supplies. However, despite their experience of upheaval to their daily life and significant personal loss, they were able to seamlessly receive care that was responsive to extant and emergent needs through telemedicine services.

As a result of climate change, natural disasters are occurring more frequently with more negative effects to human lives and settlements [3-7, 34, 35]. Individuals with disabilities are at higher risk of injury and death following natural disasters as consequence of factors that include impaired mobility and higher medical comorbidities $[36,37]$. As illustrated by this case example, when individuals with SCI experience a natural disaster, they may also face the loss of DMEs, supplies, and medications they routinely use, resulting in poorer health outcomes. Furthermore, their caregivers and their primary care providers, who live and practice in the same area, may also be affected by the disaster; thus, individuals with SCI may be unable to access and receive adequate or expeditious care. Given additional hurdles experienced by individuals with SCI, teleSCI, as an adjunct to other disaster relief services, may provide a means of delivering timely and convenient care and may facilitate swifter replacement of necessary equipment and supplies.

Research suggests that telemedicine can be an efficacious and cost-effective modality for providing care and that it may also have measurable benefits to patients, reducing the time and financial costs of attending in-person visits [38-43]. In disaster situations, a salient advantage of telemedicine is the ability to utilize remotely located providers when local and in-state resources are scarce or overwhelmed [44]. Indeed, telemedicine may circumvent sole reliance on health systems in affected areas and, for individuals with SCI and other disabilities, it may also limit travel, through potentially unsafe conditions, to seek medical care.

Recommendations have been made to have telemedicine "vigorously applied to solve medical needs in extreme and disruptive environments" [28]. In particular, recommendations suggest establishing infrastructure for telemedicine programs, principally in areas that are at high risk for disasters, so that when emergency situations are encountered, existing telemedicine networks can be used [45]. Indeed, reviews of several natural disasters suggest that instituting telemedicine capabilities after a disaster, rather than using extant infrastructure in response to disasters, is costly and may delay the provision of care $[28,29,45]$. A good example of the benefits of co-opting existing telemedicine programs during disasters is provided by the University of Texas Medical Branch's response to Hurricane Ike in 2008. Although Hurricane Ike resulted in significant disruptions to the medical center's operations, telemedicine services resumed significantly earlier and at higher levels than in-person care in the immediate aftermath of the hurricane [46]. Moreover, in another example, following a 7.6 magnitude earthquake in Pakistan in 2005, mobilization of resources at Rawalpindi's telemedicine training programs ameliorated effects of the disaster by enabling communications between affected rural clinics and preventing clinics from becoming overwhelmed [28, 47]. In our case example, an existing telemedicine service was used to provide timely and responsive care to an individual impacted by the Valley Fire within days of the start of the wildfire and before it was contained.

Apart from response to natural disasters, telemedicine has a critical role in emergency response more broadly. Indeed, the need for telemedicine and its wider integration into healthcare systems has become even more salient following the coronavirus 2019 (COVID-19) pandemic [48]. As a result of COVID-19's high transmissibility, recommendations were made to limit in-person clinic visits and to find alternatives to face-face encounters, including using telemedicine for visits [49]. However, changes to reimbursement structures had to be made to accommodate the rapid shift to telemedicine services. In particular, the Centers for Medicare and Medicaid Services temporarily expanded Medicare reimbursement to allow healthcare seekers to receive telemedicine services regardless of their location. Prior to this, Medicare reimbursed telemedicine only in limited circumstances (e.g., when healthcare seekers resided in a designated rural area and when they received telemedicine services at a medical facility) [50]. Although the use of telemedicine has grown rapidly in recent years, a combination of a number of barriers, including limited financial reimbursement, have resulted in its relatively slow uptake nationally [51-53].

In summary, scaling-up telemedicine service and incorporating routine telemedicine systems into disaster preparedness and mitigation plans may increase the likelihood of successful response to disasters. Given current research that suggests that emergency preparedness is relatively low among persons with SCI and other disabilities, a multipronged approach that incorporates disaster preparedness education and investment in infrastructure (including telemedical) that 
can be adaptively used to meet needs during natural disaster may improve post-disaster outcomes [22, 23, 25].

Acknowledgements The authors would like to thank the participants who volunteered for this study and the research coordinators and assistants who made data collection possible.

Funding Telemedicine service provided to the individual described in this case study was supported in part by the Craig H. Neilsen Foundation's Quality of Life grant \#296161 (2014-2017).

\section{Compliance with ethical standards}

Conflict of interest The authors declare that they have no conflict of interest.

Publisher's note Springer Nature remains neutral with regard to jurisdictional claims in published maps and institutional affiliations.

Open Access This article is licensed under a Creative Commons Attribution 4.0 International License, which permits use, sharing, adaptation, distribution and reproduction in any medium or format, as long as you give appropriate credit to the original author(s) and the source, provide a link to the Creative Commons license, and indicate if changes were made. The images or other third party material in this article are included in the article's Creative Commons license, unless indicated otherwise in a credit line to the material. If material is not included in the article's Creative Commons license and your intended use is not permitted by statutory regulation or exceeds the permitted use, you will need to obtain permission directly from the copyright holder. To view a copy of this license, visit http://creativecommons. org/licenses/by/4.0/.

\section{References}

1. Guha-Sapir D, Hargitt D, Hoyois P. Thirty years of natural disasters 1974-2003: The numbers. Presses Universitaires de Louvain, Louvain-la-Neuve, Belgium, 2004.

2. Van Der Vink G, Allen RM, Chapin J, Crooks M, Fraley W, Krantz J, et al. Why the United States is becoming more vulnerable to natural disasters. Eos Trans Am Geophys Union. 1998;79:533-7.

3. Cutter SL, Emrich C. Are natural hazards and disaster losses in the U.S. increasing? Eos Trans Am Geophys Union. 2005;86:381-9.

4. Keen MM, Freeman MPK, Mani MM. Dealing with increased risk of natural disasters: challenges and options. International Monetary Fund, Washington, DC, USA, 2003.

5. IPCC. In: Field, C.B., V Barros, TF Stocker, D Qin, DJ Dokken, KL Ebi, M.D. et al. editors. Managing the risks of extreme events and disasters to advance climate change adaptation. The Edinburgh Building, Shaftesbury Road, Cambridge CB2 8RU England: Cambridge University Press; 2012. p. 582. https://www.ipcc. $\mathrm{ch} /$ report/managing-the-risks-of-extreme-events-and-disasters-to-a dvance-climate-change-adaptation/.

6. Van Aalst MK. The impacts of climate change on the risk of natural disasters. Disasters. 2006;30:5-18

7. Banholzer S, Kossin J, Donner S. The impact of climate change on natural disasters. In: Singh A, Zommers Z, (eds) Reducing disaster: early warning systems for climate change. Dordrecht, Netherlands: Springer; 2014. pp. 21-49.

8. National Oceanographic and Atmospheric Administration. Climate change: global temperature; 2020. https://www.climate.gov/ news-features/understanding-climate/climate-change-globaltemperature.

9. National Oceanographic and Atmospheric Administration. Monthly and Annual U.S. Tornado Summaries. NOAA's National Weather Service: Storm Prediction Center. NOAA's National Weather Service; 2020. https://www.spc.noaa.gov/climo/online/ monthly/newm.html.

10. Federal Emergency Management Agency. Disaster declarations by year; 2020. https://www.fema.gov/disasters/year.

11. Powell R, Gilbert S. The impact of Hurricanes Katrina and Rita on people with disabilities: a look back and remaining challenges; 2015. https://ncd.gov/.

12. NC on Disability. Saving lives: including people with disabilities in emergency planning. USA: National Council on Disability; 2005.

13. Osamu N. Disaster in Japan and its Painful Lessons: Can Survivors Speak? In: Mitchell D, Karr V, (eds) Crises, conflict and disability: ensuring equality. London, UK: Routledge; 2014. p. 142.

14. National Spinal Cord Injury Statistical Center. Annual reportcomplete public version spinal cord injury model systems. National Spinal Cord Injury Statistical Center, Birmingham, AL, USA, 2018.

15. Shapiro LT, Gater Jr. DR, Espinel Z, Kossin JP, Galea S, Shultz JM. Preparing individuals with spinal cord injury for extreme storms in the era of climate change. EClinicalMedicine. 2020. https://doi.org/10.1016/j.eclinm.2019.12.002.

16. Craig A, Tran Y, Middleton J. Psychological morbidity and spinal cord injury: a systematic review. Spinal Cord. 2009;47:108-14.

17. Craig A, Nicholson Perry K, Guest R, Tran Y, Dezarnaulds A, Hales A, et al. Prospective study of the occurrence of psychological disorders and comorbidities after spinal cord injury. Arch Phys Med Rehabil. 2015;96:1426-34.

18. Krause JS, Kemp B, Coker J. Depression after spinal cord injury: relation to gender, ethnicity, aging, and socioeconomic indicators. Arch Phys Med Rehabil. 2000;81:1099-109.

19. Bombardier CH, Richards JS, Krause JS, Tulsky D, Tate DG. Symptoms of major depression in people with spinal cord injury: Implications for screening. Arch Phys Med Rehabil. 2004;85:1749-56.

20. Jensen MP, Truitt AR, Schomer KG, Yorkston KM, Baylor C, Molton IR. Frequency and age effects of secondary health conditions in individuals with spinal cord injury: a scoping review. Spinal Cord. 2013;51:882-92.

21. Brinkhof MW, Al-Khodairy A, Eriks-Hoogland I, Fekete C, Hinrichs T, Hund-Georgiadis M, et al. Health conditions in people with spinal cord injury: contemporary evidence from a populationbased community survey in Switzerland. J Rehabil Med. 2016;48:197-209.

22. McClure LA, Boninger ML, Oyster ML, Roach MJ, Nagy J, Nemunaitis G. Emergency evacuation readiness of full-time wheelchair users with spinal cord injury. Arch Phys Med Rehabil. 2011;92:491-8.

23. Hogaboom NS, Oyster ML, Riggins MS, Boninger ML. Evacuation preparedness in full-time wheelchair users with spinal cord injury. J Spinal Cord Med. 2013;36:290-5.

24. Hogan TP, Holmes SA, Rapacki LM, Evans CT, Lindblom L, Hoenig $\mathrm{H}$, et al. Disaster preparedness and response practices among providers from the Veterans Health Administration and Veterans with spinal cord injuries and/or disorders. J Spinal Cord Med. 2011;34:353-61.

25. World Health Organization, UNICEF. Guidance note on disability and emergency risk management for health. World Health Organization, UNICEF, Geneva, Switzerland, 2013.

26. Wootton R. Telemedicine. BMJ. 2001;323:557.

27. Irgens I, Rekand T, Arora M, Liu N, Marshall R, BieringSørensen F, et al. Telehealth for people with spinal cord injury: a narrative review. Spinal Cord. 2018;56:643-55. 
28. Merrell RC, Cone SW, Rafiq A. Telemedicine in extreme conditions: disasters, war, remote sites. Stud Health Technol Inform. 2008;131:99-116.

29. Garshnek V, Burkle FM Jr. Applications of telemedicine and telecommunications to disaster medicine: historical and future perspectives. J Am Med Inform Assoc. 1999;6:26-37.

30. California Department of Forestry and Fire Protection. Top 20 most destructive California Wildfires; 2020. https://www.fire.ca. gov/media/5511/top20_destruction.pdf.

31. Shem K, Sechrist SJ, Loomis E, Isaac L. SCiPad: effective implementation of telemedicine using iPads with individuals with spinal cord injuries, a case series. Front Med. 2017;4:58.

32. Sechrist S, Lavoie S, Khong C-M, Dirlikov B, Shem K. Telemedicine using an iPad in the spinal cord injury population: a utility and patient satisfaction study. Spinal Cord Ser Cases. 2018;4:71.

33. US Department of Health and Human Services. Summary of the HIPAA security rulelHHS.gov; 2020. https://www.hhs.gov/hipaa/ for-professionals/security/laws-regulations/index.html.

34. Espinel Z, Kossin JP, Galea S, Richardson AS, Shultz JM. Forecast: increasing mental health consequences from Atlantic Hurricanes throughout the 21st Century. Psychiatr Serv. 2019;70:1165-7.

35. Knutson T, Camargo SJ, Chan JCL, Emanuel K, Ho C-H, Kossin $\mathrm{J}$, et al. Tropical cyclones and climate change assessment: Part i: detection and attribution. Bull Am Meteorol Soc. 2019;100: 1987-2007.

36. Hemingway L, Priestly M. Natural hazards, human vulnerability, and disabling societies: A disaster for disabled people? Rev Disabil Stud. 2006;2:57-67.

37. Mokdad AH, Mensah GA, Posner SF, Reed E, Simoes EJ, Engelgau $\mathrm{MM}$, et al. When chronic conditions become acute: prevention and control of chronic diseases and adverse health outcomes during natural disasters. Prev Chronic Dis. 2005;2:A04-A04.

38. Dávalos ME, French MT, Burdick AE, Simmons SC. Economic evaluation of telemedicine: review of the literature and research guidelines for benefit-cost analysis. Telemed E-Health. 2009;15:933-48.

39. de la Torre-Díez I, López-Coronado M, Vaca C, Aguado JS, de Castro C. Cost-utility and cost-effectiveness studies of telemedicine, electronic, and mobile health systems in the literature: a systematic review. Telemed J E-Health. 2015;21:81-5.

40. Hailey D, Roine R, Ohinmaa A. Systematic review of evidence for the benefits of telemedicine. J Telemed Telecare. 2002;8(1_suppl):1-7.
41. Russo JE, McCool RR, Davies L. VA telemedicine: an analysis of cost and time savings. Telemed E-Health. 2015;22:209-15.

42. Dullet NW, Geraghty EM, Kaufman T, Kissee JL, King J, Dharmar M, et al. Impact of a university-based outpatient telemedicine program on time savings, travel costs, and environmental pollutants. Value Health. 2017;20:542-6.

43. Tyagi N, Amar Goel S, Alexander M. Improving quality of life after spinal cord injury in India with telehealth. Spinal Cord Ser Cases. 2019;5:70.

44. Uscher-Pines L, Fischer S, Tong I, Mehrotra A, Malsberger R, Ray K. Virtual first responders: the role of direct-to-consumer telemedicine in caring for people impacted by natural disasters. $\mathbf{J}$ Gen Intern Med. 2018;33:1242-4.

45. Latifi R, Tilley EH. Telemedicine for disaster management: can it transform chaos into an organized, structured care from the distance. Am J Disaster Med. 2014;9:25-37.

46. Vo AH, Brooks GB, Bourdeau M, Farr R, Raimer BG. University of Texas Medical branch telemedicine disaster response and recovery: lessons learned from Hurricane Ike. Telemed E-Health. 2010;16:627-33.

47. Boschert S. Disaster planning? Telemedicine is the way to go. Intern Med News. 2006;39:80-1.

48. Smith AC, Thomas E, Snoswell CL, Haydon H, Mehrotra A, Clemensen J, et al. Telehealth for global emergencies: implications for coronavirus disease 2019 (COVID-19). J Telemed Telecare. 2020;1357633X20916567. https://doi.org/10.1177/ 1357633 X20916567.

49. Centers for Disease Control and Prevention. Interim guidance for healthcare facilities: preparing for community transmission of COVID-19 in the USA; 2020. https://www.cdc.gov/coronavirus/ 2019-ncov/healthcare-facilities/guidance-hcf.html.

50. Centers for Medicare and Medicaid Services. Medicare telemedicine health care provider fact sheet; 2020. https://www.cms. gov/newsroom/fact-sheets/medicare-telemedicine-health-careprovider-fact-sheet.

51. American Hospital Association. Fact sheet: telehealth; 2020. https://www.aha.org/factsheet/telehealth.

52. Menachemi N, Burke DE, Ayers DJ. Factors affecting the adoption of telemedicine-a multiple adopter perspective. J Med Syst. 2004;28:617-32.

53. LeRouge C, Garfield MJ. Crossing the telemedicine chasm: have the U.S. barriers to widespread adoption of telemedicine been significantly reduced? Int $\mathrm{J}$ Environ Res Public Health. 2013;10:6472-84. 